\title{
AVHRR surface temperature and narrow-band albedo comparison with ground measurements for the Greenland ice sheet
}

\author{
M. HAEFLiger \\ Department of Geography, Swiss Federal Institute of Technology, CH-8057 Zurich, Switzerland
}

\begin{abstract}
K. STEFFEN
Cooperative Institute for Research in Environmental Sciences, and Dept. of Geography, University of Colorado, Boulder CO 80309, U.S.A.

C. FOWLER

Colorado Center for Astrodynamics Research, University of Colorado, Boulder CO 80309, U.S.A.
\end{abstract}

\begin{abstract}
An ice-surface temperature retrieval algorithm for the Greenland ice sheet was developed using NOAA 11 thermal radiances from channels 4 and 5 . Temperature, pressure and humidity profiles, cloud observations and skin temperatures from the Swiss Federal Institute of Technology (ETH) camp, located at the equilibrium line altitude at $49^{\circ} 17^{\prime} \mathrm{W}, 69^{\circ} 34^{\prime} \mathrm{N}$, were used in the LOWTRAN 7 model. Through a statistical analysis of daily clear sky profiles, the coefficients that correct for the atmospheric effects were determined for the ETH-Camp field season (May to August). Surface temperatures retrieved by this method were then compared against the in situ observations with a maximum difference of $0.6 \mathrm{~K}$. The NOAA 11 narrow-band planetary albedo values for channels 1 and 2 were calculated using pre-launch calibration coefficients. Scattering and absorption by the atmosphere were modelled with LOWTRAN 7 . Then, narrow-band albedo values for the AVHRR visible and near infrared channels were compared with in situ high resolution spectral reflectance measurements. In the visible band $(580-680 \mathrm{~nm})$, AVHRR-derived narrow-band albedo and the in situ measurements corrected with radiative transfer model LOWTRAN 7 showed a difference of less than $2 \%$. For the near infrared channel $(725-1100 \mathrm{~nm})$ the difference between the measured and modelled narrow-band albedo was $14 \%$. These discrepancies could be either the result of inaccurate aerosol scattering modelling (lack of the in situ observation), or the result of sensor drift due to degradation.
\end{abstract}

\section{INTRODUGTION}

Past and ongoing research indicated that several polar surface properties can be mapped through a combination of multispectral satellite data. These properties include spectrally integrated surface albedo, surface temperature and short- and long-wave radiation balance, which in turn is an important measure for the discussion of the long-term climate stability. The Greenland ice sheet provides an ideal case for the calibration of satellitederived parameters due to its large size and different homogenous snow and ice surfaces over large areas. Further, the study of seasonal and interannual variations of the above mentioned parameters provide an ideal data set to determine the "noise level" for future climate trend studies. Here the technique and some preliminary results are presented to estimate ice surface temperatures and surface albedo values from different spectral channels of the NOAA AVHRR.

\section{DATA AND METHOD}

\section{AVHRR calibration and navigation}

The advanced very high resolution radiometer (AVHRR) data used in this study were obtained from National Oceanographic and Atmospheric Research Laboratories (NOARL). This is the local area coverage (LAC) data in level 1b format from the NOAA-11 satellite, and includes 5 channels: 2 visible and 3 infrared. The level 1b format includes information for the navigation and calibration of the images (Lauritson and others, 1979), but this information was re-done on site to gain more control over the processing of the data. The navigation of the AVHRR data can be used to better depict the actual motion of the satellite (Baldwin and Emery, 1993). A small registration error is present in the resulting images that are removed by linearly nudging the images onto a map grid. Images from each of the days are 
are then compared with each other. Registration errors can then be reduced to $\pm \frac{1}{2}$ pixel. The navigation of the data was mapped to a polar stereographic projection with a $1 \mathrm{~km}$ per pixel resolution. The resolution of the scan spot from the AVHRR instrument varies from $1.1 \mathrm{~km}$ at nadir to about $6.8 \mathrm{~km}$ at a scan angle of $55^{\circ}$. This is not a linear function; a scan angle of $30^{\circ}$ still results in a pixel resolution of about $1.5 \mathrm{~km}$.

Calibration of the AVHRR imagery is channel dependent. Calibration of the reflected solar energy "visible" channels, 1 and 2, is done by using pre-launch values particular to each satellite. These values (Kidwell, 1991) convert the instrument counts into per cent albedo. Solar zenith angles are computed during the navigation procedure for each pixel in the image and corrections made to the per cent albedo. Channel 3 is a combination of reflected and emitted energy during daylight conditions and was not used in this paper. The emitted infrared channels, 4 and 5, require several steps for calibration. First, continuous on-board sensing of space and blackbody targets every few scan lines provides information for computing slope and intercept values for the infrared channels (Lauritson and others, 1979). Energy values are calculated, and then using Planck's equation with prelaunch wavenumbers, brightness temperatures can be found. Non-linear corrections that are dependent upon the scene temperature are then applied. These non-linear corrections were on the order of $-1.0^{\circ}$ for the observed area.

\section{Ice-surface temperature}

A common approach for estimating surface temperatures is to relate satellite data to surface temperature observations with a regression model. The radiative transfer equation can be applied to model satellite radiances and brightness temperatures. A common approach to retrieve surface temperatures is to use the split-window infrared AVHRR channels 4 and $5(10.5-11.5 \mu \mathrm{m}, 11.5-12.5 \mu \mathrm{m})$ as was applied for open-ocean areas (McClain and others, 1985; Minnett, 1990) as well as sea-ice areas (Key and Haefliger, 1992). To correct for atmospheric attenuation of the satellite measured brightness temperatures over the Greenland ice sheet the surface temperatures are regressed against modelled AVHRR brightness temperatures as described by Key and Haefliger (1992). Atmospheric attenuation was derived with the radiative transfer model LOWTRAN 7 (Kneizys and others, 1988) using radiosonde profile measurements from the ETH-Camp (Federal Institute of Technology (ETH), Department of Geography (Fig. 1)) as input data. A total of 78 radiosondes were launched from 8 June through 29 August 1990, and 194 from 13 May through 21 August 1991. The profiles include pressure, temperature and relative humidity for every second up to a height of 20 $25 \mathrm{~km}$ (Fig. 2). Continous incoming and outgoing longwave radiation measurements and daily cloud observations ( 7 times each day) were also available from the ETH Camp. The longwave radiation at the ETH Camp was calculated as the difference between the allwave radiation, measured by pyrradiometers, and the short-wave radiation, measured by pyranometers, and compensated for by the emission-loss from the instrument.

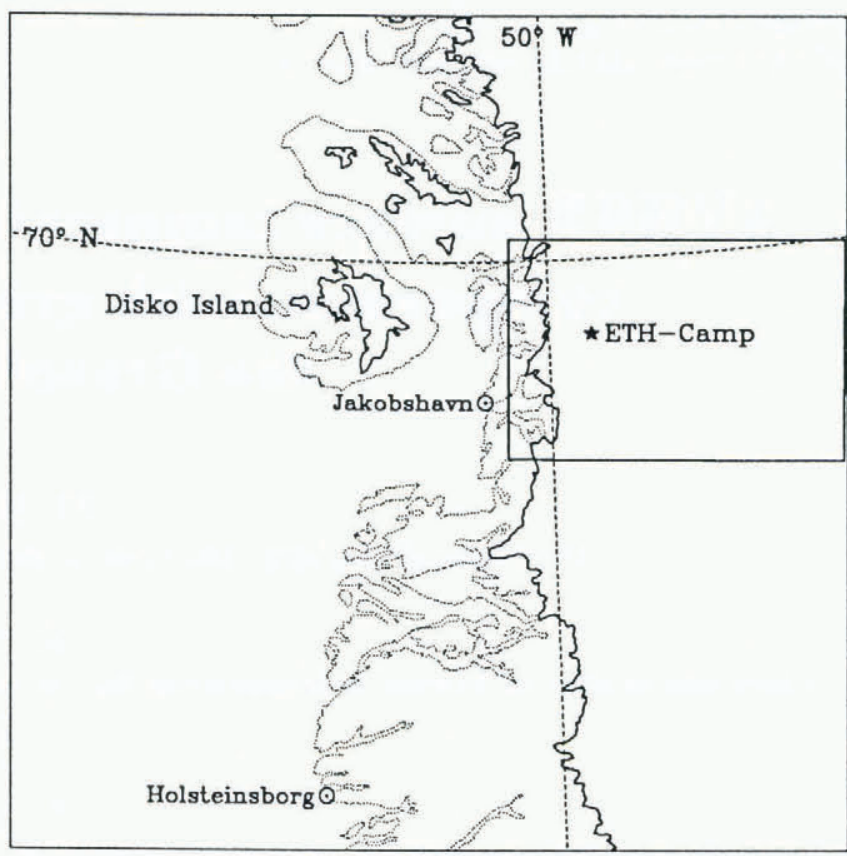

Fig. 1. Overview of Disco Bay in West Greenland $(560 \times 560 \mathrm{~km})$. The rectangular area around the ETH Camp $(152 \times 227 \mathrm{~km})$ is the test area to which the coefficients are applied (dotted lines $=$ coast, solid line $=$ ice margin).

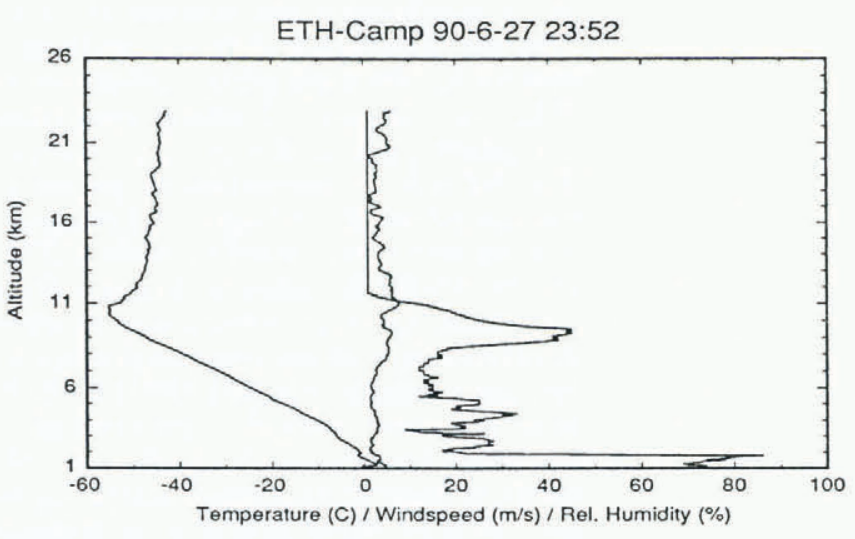

Fig. 2. Radiosonde profile measurements of temperature, relative humidity, and wind speed from the ETH Camp, located at the equilibrium line altitude on the Greenland ice sheet $\left(49^{\circ} 17^{\prime} \mathrm{W}, 69^{\circ} 34^{\prime} \mathrm{N}\right)$.

The pyrradiometers were calibrated over a melting ice surface. Only situations with less than $\frac{3}{8}$ cloud cover were used in the analysis, which are referred to as "clear sky" conditions. A total of 90 profiles remained with clear sky conditions.

The surface temperature at the camp is calculated from the outgoing longwave irradiance with the StefanBoltzmann law: $R=\sigma T^{4}$, assuming the snow surface is a black-body. In general the longwave irradiance measurements have an error of $\pm 10 \mathrm{~W} \mathrm{~m}^{-2}( \pm 3 \%)$ or even better in case of the Greenland measurements (personal communication from $\mathrm{T}$. Konzelmann). To every measured outgoing longwave irradiance $3 \%$ are added and subtracted, respectively. This way three new profiles are 
created out of each of the 90 original clear sky ones, where the surface temperatures are the minimum

$$
\left(T_{\min }=\left(\frac{R_{-3 \%}}{\sigma}\right)^{\frac{1}{4}}\right), \quad \text { mean }\left(T_{\text {mean }}=\left(\frac{R}{\sigma}\right)^{\frac{1}{4}}\right),
$$

and the maximum

$$
\left(T_{\max }=\left(\frac{R_{+3 \%}}{\sigma}\right)^{\frac{1}{4}}\right)
$$

calculated temperatures, respectively. This results in a sample size of 270 clear sky profiles.

To eliminate the influence of the atmosphere on the signal reaching the satellite, the measurements of at least two spectral bands are required. A good overview of the theoretical algorithms for satellite-derived SSTs is presented in Barton and others (1989). The method used in this study is the same as described in Key and Haefliger (1992) and reads as following:

$$
T_{\text {ice }}=a+b T_{4}+c T_{5}+d\left[\left(T_{4}-T_{5}\right) \mathrm{s}(\Theta)\right] .
$$

$T_{4}$ and $T_{5}$ are the satellite-measured brightness temperatures in Kelvin and $\Theta$ is the sensor scan angle $\left(0-55^{\circ}\right)$. The coefficients are determined through a least-squares regression procedure. Surface temperatures are regressed against modelled brightness temperatures. LOWTRAN 7 is used to simulate radiances in the AVHRR thermal channels 4 and 5, which are then converted to brightness temperature.

The coefficients for the estimation of ice surface temperature (IST) according to Equation (1) are shown in Table 1 . The root mean square (RMS) error of $0.3 \mathrm{~K}$ is well within the error of the outgoing longwave measurements which is $\pm 1 \mathrm{~K}$ for the Greenland measurements. Table 2 shows the calculated IST for the AVHRR pixel representing the location of the ETH Camp. Due to the uncertainty of the exact location (AVHRR geolocation error), the temperature of $3 \times 3$ pixels are calculated and compared to the in situ measurement of the camp. The comparison of AVHRR-derived ice surface temperatures with the in situ measurements show differences of up to $0.6 \mathrm{~K}$. The regional variation of ice surface temperatures around the ETH Camp are shown in Figure 3 (see also Figure 1 for overview of area).

\section{Planetary and surface narrow-band albedo}

In the presented case study, the planetary narrow-band albedo for AVHRR channels 1 and 2, measured on 23 May 1991, will be compared against ground-based values measured with a portable spectrometer. The Geophysical Research Corporation (GER) portable field spectrometer measures reflectance values for 875 different spectral bands between 300 and $2500 \mathrm{~nm}$ (Table 3 ). The spectrometer was regulated with a laptop computer (SNAP $1+1)$ which was also used for data acquisition. The fieldof-view of the optical head is $7^{\circ}$ in horizontal and $1.6^{\circ}$ in vertical direction (rectangular area of sensitivity given by the photodetector array). An integration sphere was mounted in front of the optical head for hemispheric measurements which could be directed towards the zenith or perpendicular to the ground which was used to
Table 1. Coefficients and RMS error based on NOAA 11 AVHRR channels 4 and 5

\begin{tabular}{ccccc}
\hline$a$ & $b$ & $c$ & $d$ & RMS \\
-4.257151 & 3.473293 & -2.470502 & -0.141503 & 0.320 \\
\hline
\end{tabular}

Table 2. Measured and calculated AVHRR ice-surface temperature (IST) at the ETH Camp

\begin{tabular}{cccc}
\hline Date & Measured IST & Calculated IST & Delta IST \\
1990 & $\mathrm{K}$ & $\mathrm{K}$ & $\mathrm{K}$ \\
& & & \\
\hline & & & \\
21 June & 271.1 & 271.6 & +0.5 \\
23 June & 271.3 & 271.0 & -0.3 \\
24 June & 271.5 & 271.1 & -0.4 \\
27 June & 271.3 & 270.8 & -0.5 \\
28 June & 271.3 & 271.1 & -0.2 \\
29 June & 270.2 & 270.7 & +0.5 \\
1 July & 271.9 & 271.3 & -0.6 \\
2 July & 271.1 & 271.5 & +0.4 \\
\hline
\end{tabular}

Table 3. Specification for the GER-spectrometer

\begin{tabular}{ccc}
\hline Range & Resolution & Number of Channels \\
$\mathrm{nm}$ & $\mathrm{nm}$ & \\
& & \\
\hline $300-600$ & 1.5 & 199 \\
$600-1050$ & 1.7 & 266 \\
$1050-1800$ & 3.0 & 245 \\
$1800-2500$ & 4.2 & 165 \\
\hline
\end{tabular}

measure the spectral reflectance of the snow surface. The spectral reflectance of the snow surface is shown in Figure 4. The snow was fresh, less than one day old, with grain sizes between $0.1-0.2 \mathrm{~mm}$ in diameter. The prevailing air temperature was well below freezing. In addition to the spectrometer measurements broadband global radiation, and diffuse and reflected shortwave radiation were measured with a set of pyranometers as part of the ongoing radiation balance experiment at the ETH Camp. The reflected shortwave radiation was measured at $1.5 \mathrm{~m}$ and at $27 \mathrm{~m}$ above the surface. The 


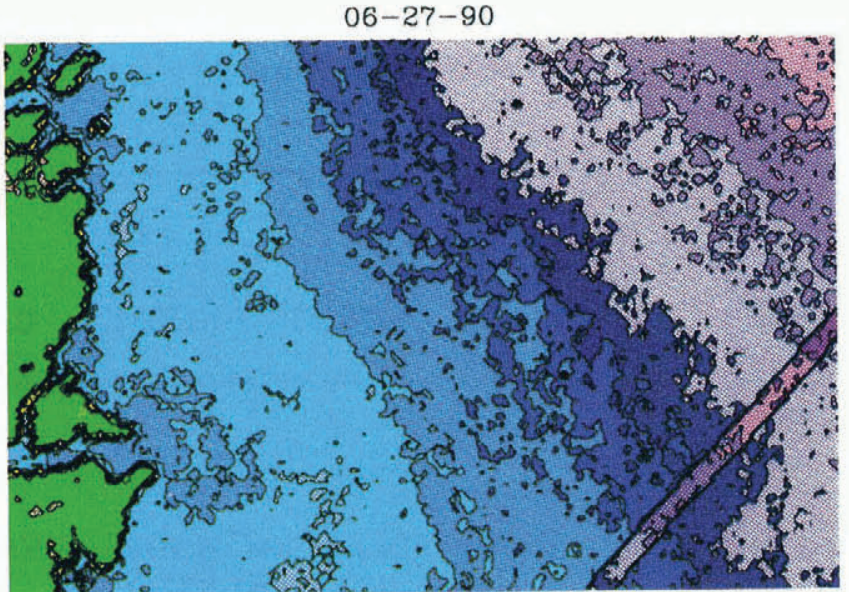

$06-28-90$

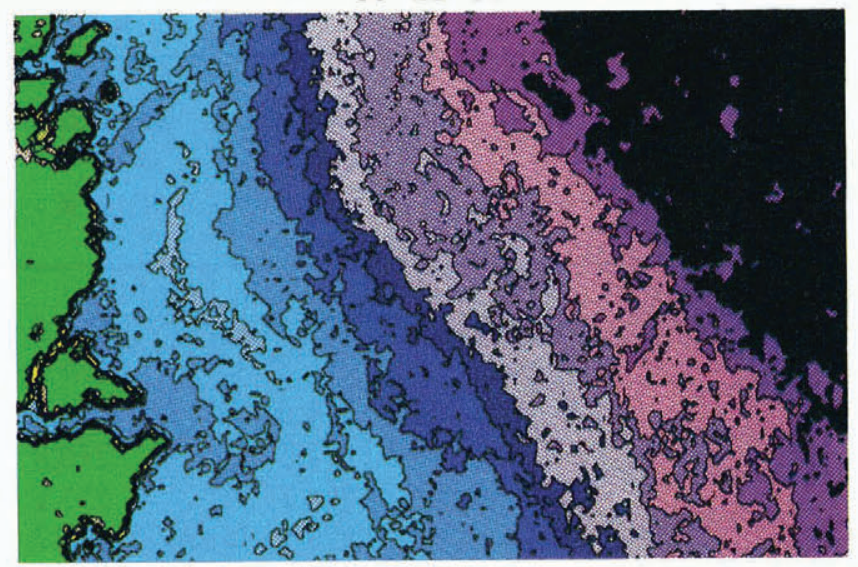

06-29-90

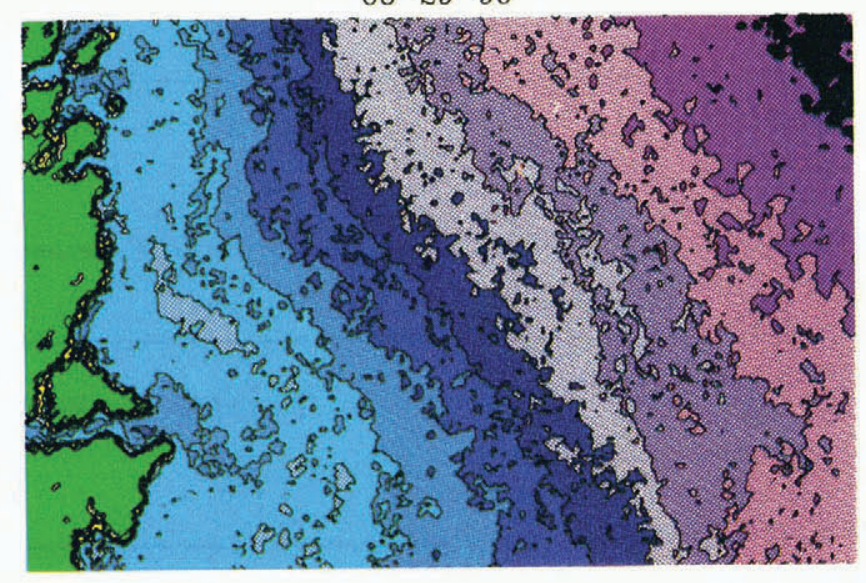

$<280.0$

277.5

276.5

275.5

274.5

273.5

272.5

271.5

270.5

269.5

268.5

267.5

266.5

265.5

264.5

263.5

$>260.0$

Fig. 3. Ice-surface temperatures around the ETH camp (see Fig. 2). The variation from day to day is shown. The image of 26 June contains an error in a few scan lines, visible in the lower right corner.

broadband albedo values derived from the pyranometers were $84.3 \%$ for the lower instrument, and $82.2 \%$ for the instrument at $27 \mathrm{~m}$. The slightly lower albedo value for the later can be explained by the larger field-of-view which included part of the field camp as well as surface roughness in the scale order of meters and larger. The spectrally-integrated reflectance derived from the spectrometer is $82.9 \%$ which shows the level of accuracy $(\delta=0.7 \%)$ which can be expected using two different kind of instruments.

The narrow-band albedo measured by the AVHRR sensors $(i=1,2)$ is computed as a linear function of the input value $C$ and the pre-launch calibration coefficients as follows (Kidwell, 1991):

$$
A=S(i) C+I(i)
$$

with $S(1)=0.095, S(2)=0.1061, I(1)=-3.8, I(2)=$ -3.6 for NOAA 11 .

This calibration takes the spectral response of the channels $(i=1,2)$ into account by multiplying the spectral irradiance viewed at the top of the atmosphere with the spectral response function. NOAA 11 satellite data from the ETH Camp area were collected on 23 May 


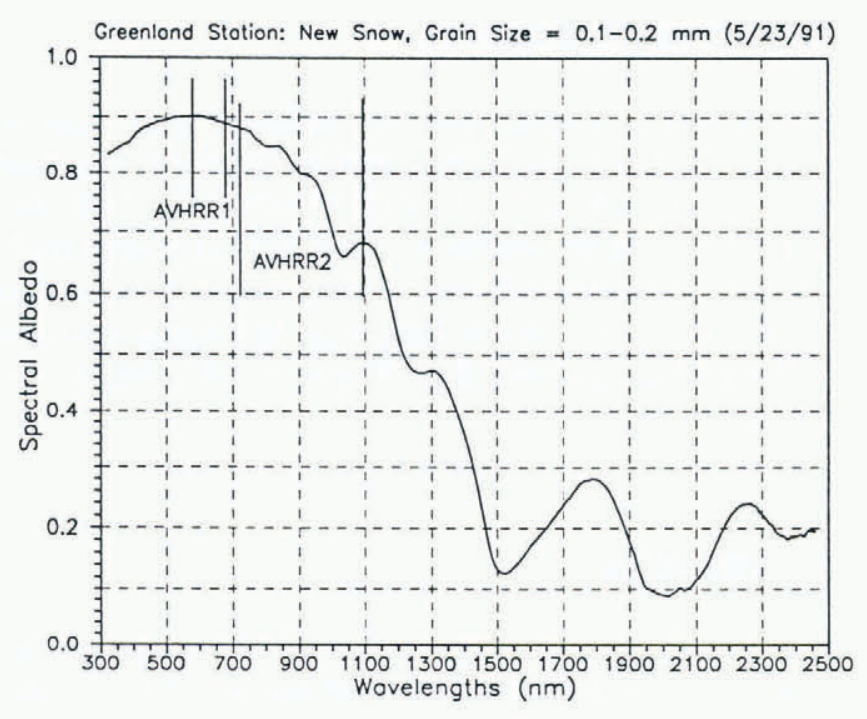

Fig. 4. Spectral reflectance of new snow (grain size 0.1$0.2 \mathrm{~mm}$ ), pre-melt period.

1991, 15.11 GMT with a satellite zenith angle relative to the camp of $27.37^{\circ}$ and a solar zenith angle of $49.16^{\circ}$. The narrow-band planetary albedo values for AVHRR channels 1 and 2 are listed in Table 4 . The accuracy of the AVHRR-derived narrow-band albedo values are discussed in the following.

The atmospheric absorption and scattering was modelled using the radiative transfer code LOWTRAN 7. Two model runs were performed: (a) using the in situ radiosonde profile measurements of temperature and humidity as input data, and (b) using the standard subarctic atmosphere. Figure 5 depicts the solar irradiance at the top of the atmosphere and the irradiance as modelled with LOWTRAN 7 at the surface using radiosonde profile measurements. The narrow-band albedo at the top of the atmosphere $a_{\mathrm{p}}$ was then calculated by integrating over the AVHRR spectral band-width $\left(\lambda_{1}, \lambda_{2}\right)$, as following:

$$
a_{\mathrm{p}}=\frac{\int\left[S(\lambda) \oslash_{\mathrm{i}}(\lambda) \tau(\lambda) a_{\mathrm{g}}(\lambda)\right] \mathrm{d} \lambda}{\int\left[S(\lambda) \oslash_{\mathrm{i}}(\lambda)\right] \mathrm{d} \lambda}
$$

where $S(\lambda)$ is the solar irradiance at the top of the atmosphere, $\oslash_{i}(\lambda)$ is the spectral response function of the AVHRR channel $(i=1,2), a_{\mathrm{g}}(\lambda)$ is the narrow-band reflectance at the ground, and $\tau(\lambda)$ is the calculated spectral transmission for two path lengths: (a) between the top of the atmosphere and the surface, and (b) between the surface and the satellite. The integration was done for both AVHRR channels with (a) radiosonde profile data and (b) standard sub-Arctic atmosphere (Table 4). The difference between measured and calculated narrow-band planetary albedo for channel 1 is $0.5 \%$ using radiosonde profile data in the LOWTRAN 7 model. For the standard sub-Arctic atmosphere, the difference increased to $2.9 \%$. However, for AVHRR channel 2 the calculated and measured narrow-band albedo values differ by approximately $9 \%$. Surface narrow-band albedo $a_{\mathrm{g}}$ can also be derived from planetary narrow-band albedo $a_{\mathrm{p}}$ values as following:
Table 4. Narrow-band albedo values for AVHRR channels 1 and 2 as measured by AVHRR at the top of the atmosphere $\left(a_{\mathrm{p}}=\right.$ planetary narrow-band albedo $)$, and calculated using ground-based spectrometer values $a_{\mathrm{g}}$ and radiative transfer modelling

\begin{tabular}{ccccc}
$\begin{array}{c}\text { AVHRR } \\
\text { Channel }\end{array}$ & $a_{\mathrm{p}}$ & $\begin{array}{c}\text { Calculated } a_{\mathrm{p}} \\
\text { with radiosonde }\end{array}$ & $\begin{array}{c}\text { Calculated } a_{\mathrm{p}} \\
\text { with standard } \\
\text { atmosphere }\end{array}$ & $a_{\mathrm{g}}$ \\
& $\%$ & $\%$ & $\%$ & $\%$ \\
& & & & \\
& & & & \\
\hline $1(580-680 \mathrm{~nm})$ & 68.8 & 67.5 & 65.5 & 91.6 \\
$2(725-1100 \mathrm{~nm})$ & 56.1 & 65.2 & 64.5 & 81.0 \\
\hline
\end{tabular}

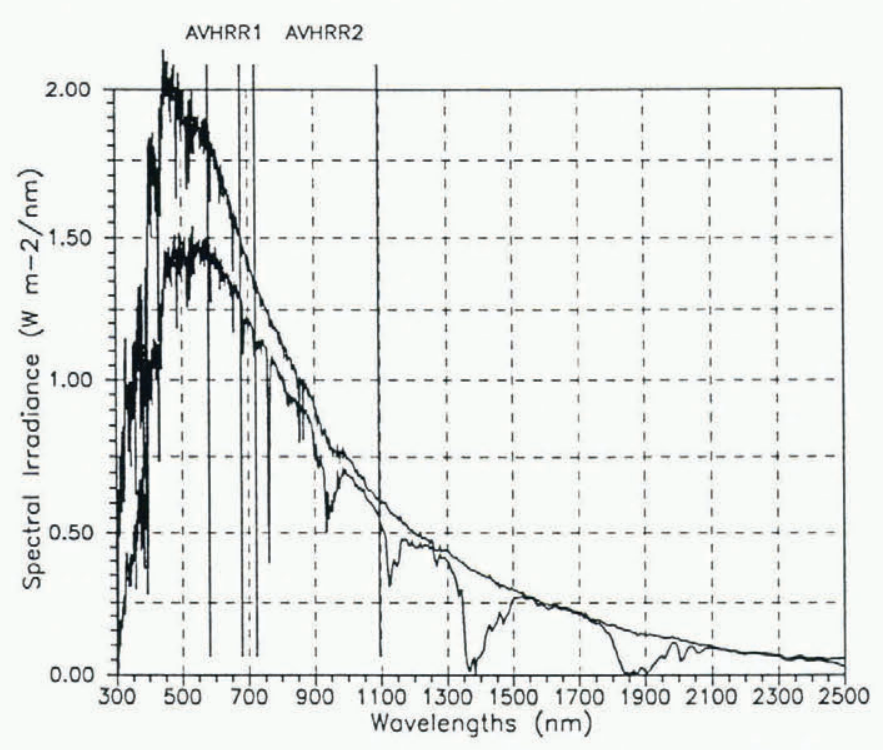

Fig. 5. Solar irradiance outside the atmosphere, and at the surface as modelled by LOWTRAN 7 radiative transfer model with the in situ radiosonde data for 23 May, 15.11 GMT.

Table 5. Narrow-band surface albedo values $a_{\mathrm{g}}$ compared against calculated surface narrow-band albedo from AVHRR channels 1 and 2 using transmission coefficients $\tau_{1}$ (sun-surface), and $\tau_{2}$ (surface-satellite)

\begin{tabular}{lccccc}
$\begin{array}{l}\text { AVHRR } \\
\text { Channel }\end{array}$ & $a_{\mathrm{g}}$ Calculated & $\begin{array}{c}\text { Calculated } \\
a_{\mathrm{g}} \text { with } \\
\text { radiosonde }\end{array}$ & $\begin{array}{c}a_{\mathrm{g}} \text { with } \\
\text { standard } \\
\text { atmosphere }\end{array}$ & $\tau_{2}$ \\
& & & & \\
& $\%$ & $\%$ & $\%$ & & \\
& & & & & \\
\hline & & & & & \\
$1(580-680 \mathrm{~nm})$ & 91.6 & 93.3 & 95.1 & 0.825 & 0.895 \\
$2(725-1100 \mathrm{~nm})$ & 81.0 & 69.3 & 70.3 & 0.878 & 0.922
\end{tabular}




$$
a_{\mathrm{g}}=\frac{a_{\mathrm{p}}}{\left[\tau_{\text {(sun-surface) }}(\lambda) \tau_{\text {(surface-satellite) }}(\lambda)\right]} .
$$

The transmission values were calculated with the radiative transfer model which takes the intrinsic atmospheric reflectance due to the Rayleigh and aerosol scattering of the standard sub-Arctic atmosphere into account. The surface narrow-band albedo values derived from the AVHRR planetary albedo are given in Table 5 . The differences have the same order of magnitude for the calculated planetary narrow-band albedo which is not surprising as both computations use the LOWTRAN 7 model with identical input parameters.

So far, we have neglected the bidirectional reflectance (BR) of a snow surface as a possible error due to large scanner angle and large solar zenith angle (Steffen, 1987). It can be assumed that the snow has an isotropic reflectance for the small satellite zenith angle encountered during this study. For satellite zenith angles of $50^{\circ}$ or larger, the BR of snow has to be taken into account, especially for wet snow surface. The in situ measurements of aerosol distribution with height were not available. This might be an additional error source. Aerosol content can vary with time and space significantly which can reduce the reflectance by several per cents. If we assume that the radiative transfer model is correct, we can speculate that a major sensor drift of AVHRR channel 2 has occurred since launch of NOAA 11 on 8 November 1988. For the visible channel of NOAA 9 degrading rates of up to $6 \%$ per year were found (Staylor, 1990). This case study should be judged as a preliminary analysis, as more cases have to be compared to get a statistically significant error analysis. Further, we have to find a means to validate the LOWTRAN 7 derived spectral transmission values, in order to separate the modelling error from the error caused by the sensor drift.

\section{SUMMARY AND CONCLUSION}

The relationship between clear sky NOAA 11 thermal radiances and the measured surface temperature of the Greenland ice sheet is examined through forward calculations of radiative transfer equation. Pressure, temperature and relative humidity profiles and cloud observation from the ETH Camp are used. Using the split window channels 4 and 5 and scan angle, the RMS error in the estimated IST is $0.3 \mathrm{~K}$.

Narrow-band surface albedo values can be estimated from AVHRR channel 1 and 2 measurements with an accuracy of $2 \%$ and $14 \%$ respectively, using LOWTRAN 7 radiative transfer modelling and radiosonde profile information. More case studies are needed to discuss this technique in more depth and to derive statistically significant values.

\section{ACKNOWLEDGEMENTS}

This research was funded by NASA Ocean Science Branch (Grant NAG 5-882), and by the Swiss National Science Foundation (Grants 20-2571.88 and 2127449.89). Thanks are due to the ETH expedition team for collection of the radiation and radiosonde data, and to A. Ohmura and T. Konzelmann, Swiss Federal Institute of Technology, and to J. Key, University of Colorado, for useful discussions.

\section{REFERENGES}

Baldwin, D. G. and W.J. Emery. 1993. A systemized approach to AVHRR image navigation. Ann. Glaciol., 17 (see paper in this volume).

Barton, I.J., A. M. Zavody, D. M. O'Brien, D. R. Cutten, R.W. Saunders and D. T. Llewellyn-Jones. 1989. Theoretical algorithms for satellite-derived sea surface temperatures. 7. Geophys. Res., 94(D3), 3365-3375.

Key, J. and M. Haefliger. 1992. Arctic ice surface temperature retrieval from AVHRR thermal channels. F. Geophys. Res., 97(D5), 5885-5893.

Kidwell, K. 1991. NOAA polar orbiter data user's guide. Washington, DC, U.S. Department of Commerce. National Oceanic and Atmospheric Administration.

Kneizys, F.X. and 7 others. 1988. User's guide to LOWTRAN 7. Bedford, MA, Air Force Geophysics Laboratory. (Environmental Research Papers 1010.)

Lauritson, L., G.J. Nelson and F.W. Porto. 1979. Data extraction and calibration of radiometers. NOAA Tech. Memo. NESS 107.

McClain, E. P., W. G. Pichel and C. C. Walton. 1985. Comparative performance of AVHRR-based multichannel sea surface temperatures. 7. Geophys. Res., 90(C6), 11,587-11,601.

Minnett, P.J. 1990. The regional optimization of infrared measurements of sea surface temperature from space. 7. Geophys, Res., 95(C8), 13,497-13,510.

Staylor, W.F. 1990. Degrading rates of the AVHRR visible channel for the NOAA 6,7 , and 9 spacecraft. $\mathcal{J}$. Atmos. Oceanic Technol., 7, 411-423.

Steffen, K. 1987. Bidirectional reflectance of snow at 500 $600 \mathrm{~nm}$. International Association of Hydrological Sciences Publication 166 (Symposium at Vancouver 1987 Large Scale Effects of Seasonal Snow Cover), 415-425.

The accuracy of references in the text and in this list is the responsibility of the authors, to whom queries should be addressed. 